\title{
Capsule Commentary on Shih et al., Functional Status Outperforms Comorbidities in Predicting Acute Care Readmissions in Medically Complex Patients
}

\author{
Phil St John, MD, MPH, FRCPC \\ Head, Section of Geriatric Medicine, University of Manitoba, Winnipeg, Canada.
}

J Gen Intern Med 30(11): 1703

DOI: $10.1007 / \mathrm{s} 11606-015-3384-5$

(c) Society of General Internal Medicine 2015

$\mathrm{W}$ e know very intimate details about our patients - the pressure inside their right ventricle, the concentration of ions in their blood, and the diameter of their blood vessels. But we often don't know if they can walk, think, or feed themselves. For decades, we have known that functional status predicts outcomes of persons in their homes, in hospitals, and health care facilities. Moreover, many people see functional autonomy as an endpoint in its own right, not just as a predictor of adverse outcomes.

Measuring functional status in hospitalized individuals is not particularly difficult or novel, ${ }^{1}$ yet it is a very strong predictor of in-hospital death. ${ }^{2}$ Recent reports also indicate that it predicts readmission after discharge from acute care. ${ }^{3}$ Shih et al. go on to show that functional status predicts 30-day readmission in patients recently discharged from rehabilitation facilities. ${ }^{4}$ While not completely accurate, models incorporating functional status measures were found to be superior to models incorporating only demographic and disease-based measures. Considering other factors - notably social networks and supports, social resources, and adequacy of follow-up care-may further improve accuracy.

While this is hardly surprising, it is important. First, casemix adjustment models for readmission will be highly inaccurate if they do not consider functional capacity, and this inaccuracy could distort incentives to providers. Second, inpatient care models which reduce the risk of functional decline $^{5}$ may also reduce the risk of readmission. Third, we should consider targeting individuals with greater disability for earlier and more intensive post-discharge follow-up.

Further study into functional trajectories is also needed. Functional status is a dynamic process, dependent on a variety of factors. Patients with improving functional status may be at less risk than those with deteriorating function. The role of functional status in determining other longer-term outcomes, such as death after discharge, should also be examined. However, we should not wait on the results of these studies. We must start measuring functional status, and we should adopt hospital care models which prevent functional decline sooner rather than later.

Conflict of Interest: The author declares that he does not have a conflict of interest.

Corresponding Author: Phil St John, MD, MPH, FRCPC; Head, Section of Geriatric MedicineUniversity of Manitoba, Winnipeg, Canada (e-mail: pstjohn@hsc.mb.ca).

\section{REFERENCES}

1. Arnold J, Exton-Smith AN. The geriatric department and the community value of hospital treatment in the elderly. Lancet. 1962;280(7255):551-3.

2. Covinsky KE, Justice AC, Rosenthal GE, Palmer RM, Landefeld CS. Measuring prognosis and case mix in hospitalized elders. The importance of functional status. J Gen Intern Med. 1997;12(4):203-8.

3. Greysen SR, Stijacic Cenzer I, Auerbach AD, Covinsky KE. Functional impairment and hospital readmission in medicare seniors. JAMA Int Med. 2015; 175(4):559-65.

4. Shih SL, Gerrard, Goldstein R, Mix J, Ryan ZCM, Niewczyk P, Kazis L, Hefner J, Ackerly DC, Zabonte R, Schneider JC. Functional Status Outperforms Comorbidities in Predicting Acute Care Readmissions in Medically Complex Patients. J Gen Intern Med. doi:10.1007/s11606-015-3350-2

5. Ellis G, Whitehead MA, O'Neill D, Langhorne P, Robinson D. Comprehensive geriatric assessment for older adults admitted to hospital. Cochrane Database Syst Rev (Online). 2011;7:CD006211. 